\title{
Роля на 18F-FDG ПЕТ/KТ в диагностичния алгоритъм при злокачествените епителни тумори на глава и шия
}

\author{
Цв. Йорданова', А. Клисарова', Г. Илиев², П. Иванова², \\ М. Милков ${ }^{3}$, Хр. Ивановска ${ }^{4}$, Е. Енчева ${ }^{4}$ \\ 'Клиника по нуклеарна медицина и метаболитна терапия към \\ УМБАЛ „Света Марина“ - Варна - Медицински университет - Варна \\ ${ }^{2}$ Клиника по УНГ болести към УМБАЛ „Света Марина“ Варна - Медицински университет Варна \\ ${ }^{3}$ Faculty of Dental Medicine, Medical University of Varna \\ ${ }^{4}$ Radiotherapy Department, St. Marina University Hospital, Medical University of Varna
}

\begin{abstract}
Резюме
Туморите на глава и шия са хетерогенна група с разнообразна локализация. Епителните тумори на глава и шия, от които $90 \%$ са с плоскоклетьчна хистология, имат сходно развитие, което определя еднотипния диагностичен подход при тях. Целта на настоящия обзор е да направи преглед на литературните данни, касаещи ролята на 18F-FDGПET/КТ в диагностичния алгоритъм при злокачествени тумори на глава и шия. Проучванията сочат, че целотелесният хибриден образен метод има важна роля при нодално и далечно стадиране, рестадиране, преценка за терапевтичен подход, оценка ефекта от лечение, ранна визуализация на рецидиви, скринингова детекция на синхронни/метахронни тумори и далечни метастази, дори без клинична изява. При пациенти с доказани метастатични шийни лимфни възли с плоскоклетьчна хистология FDG-ПЕТ/КТ помага за водене на насочена биопсия (панендоскопия) и откриване на първично туморно огнище. По-голям брой от пациентите са в напреднал стадий при установяване на заболяването. Точното стадиране с целотелесно FDG-ПЕT/КТ изследване, ранна визуализация на далечни метастази и втори първичен тумор при пациенти с епителни злокачествени тумори на глава и шия позволява своевременна промяна на терапевтичния подход, избор на индивидуален терапевтичен план и своевременно лечение според нуждите на пациента.

Ключови думи: 18F-FDGПET/КТ, диагностичен алгоритъм, тумори на глава и шия, насочена биопсия, терапевтичен ефект, метастатични шийни лимфни възли
\end{abstract}

поред българския Национален раков
регистър всяко от заболяванията на
глава и шия е с ниска честота, но като група заболеваемостта и смъртността в нашата страна през 2013 г. са съответно 22,2/100 000 и 11,5/100 000.(1) Рискови фактори за развитие на злокачествените заболявания на глава и шия са тютюнопушене и алкохол. Те водят до развитие на синхронни тумори с локализация в белия дроб или езофага. В метаанализ Mehanna $\mathrm{H}$ et al. установяват, че човешкият папилома вирус (HPV-16) е чест причинител на туморите на орофаринкс. (2) Туморите на глава и шия са разнообразна група, които според локализацията си се разделят на подгрупи: тумори на носна кухина и параназални синуси, назофаринкс, хипофаринкс, ларинкс и трахея, тумори на устна кухина и орофаринкс и тумори на слюнчени жлези. Най-често срещаният хистологичен вариант при злокачествените епителни туморни на глава и шия е плоскоклетъчният карцином, който е 90\%. Поради твърде сложните анатомични особености на всяка област стадирането на злокачествените тумори на глава и шия е комплицирано, поради което Американският обединен комитет по рака (АJCC) насочва усилията си да включи туморите от различни локализации в TNM класификация, която е специфична за отделните локализации. Точното 
стадиране на раковите заболявания е важно за избора на лечение, за предсказване на резултатите от него и прогнозата. Епителните плоскоклетъчни тумори на глава и шия имат сравнително логично и предвидимо развитие. По-голям брой от пациентите (почти 66\%) са в напреднал стадий при установяване на заболяването. Почесто злокачествените тумори на глава и шия (ЗТГШ) се срещат при възрастни мъже, пушачи и консумиращи алкохол. Превалира по-честото възникване на тези видове карциноми при мъже, отколкото при жени, като средната въ3раст за поява е в 6-тата декада. (3) Една трета от пациентите със злокачествени тумори на глава и шия при презентацията си са в I или II клиничен стадий, по-често тези тумори при диагностицирането си са в напреднал стадий. Синхронните първични тумори са една от основните причини за смърт при ранен стадий на плоскоклетъчните карциноми на глава и шия. (4) Вероятността за метастази в шийни лимфни възли се определя от локализацията на първичния тумор, стадия на заболяването и хистологията. (5) При пациенти с метастатични шийни лимфни възли се установява лоша прогроза и намаляване на преживяемостта, което насочва усилията на образните изследвания за точно нодално стадиране, позволяващо навременно лечение в шийната област. Детекцията на далечни метастази променя прогнозата и терапевтичното поведение при ЗТГШ. (6) Ранното и точно далечно стадиране при тези пациенти позволява избор на индивидуален терапевтичен подход и своевременно лечение, според нуждите на пациента. Стадирането на злокачествените епителни тумори на глава и шия се базира на резултата от клиничния преглед след ендоскопия и данните от конвенционалните образни методи магнитнотомографската томография (МРТ), компютьр томографското изследване с контраст (сеКТ) и ехографско изследване. Ехографското изследване е безвредно и достъпно изследване, метод на избор при суспектни шийни лимфни възли. Компютьрната томография (KT) дава информация за дълбочина, размери на тумора, наличието на ангажирани съседни структури и шийни лимфни възли. Визуализира добре костните структури. Затруднено при КТ изследването е разграничаване на постоперативни или постлъчетерапевтични промени от рецидив, както и наблюдаване на фалшиво негативни резултати при първични глотисни карциноми и мукозни карциноми със суперфициално разпространение. (7) Магнитнорезонансната томография (МРТ) е предпочитан метод пред КТ при изследване на деца, поради липсата на йонизиращо лечение. Предимство на този метод пред КТ е добрата делинеация на тъканите (особено в назофаринк основата на черепа и орофаринкс), визуализиране на структурите в дълбочина и представянето им като 3D образ, което позволява точна анатомична локализация на патологичните находки, без използване на венозен котраст. (8) При Т-стадиране на тумори в глава и шия на супрахиоидната част на шията се провежда МРТ, а при инфрахиоидна локализация (в ларинкс, хипофаринкс) КТ. При некатегорични резултати от конвенционалните образни методи (КТ, МРТ) за малигнено ангажиране на шийни лимфни възли е уместно провеждане на ПЕТ/КТ или тънкоигленна аспирационна биопсия.

Позитронноемисионна томография с компютърна томография (ПЕТ/КТ) е хибридно образно изследване за морфологична и функционална диагностика, с утвърдена роля при ЕТГШ. Методът позволява едноетапно целотелесно сканиране на пациентите, отличаващо го от конвенционалните образни методи. ПЕТ има дълго развитие, като днес се използва за клинични и изследователски цели. С най-бурно развитие сред методите за функционална образна диагностика в Европа, Америка и Азия е ПЕТ, която след 2000 год. получава нов тласък с появата на интегрираната техника - позитронноемисионна томография с компютърна томография (ПЕТ/КТ). За пръв път в България 18F-FDG ПЕТ/КТ се използва през 2009 год. в УМБАЛ „Св. Марина““ - Варна и за първи път се прилагат и утвърждават протоколи за изследване на пациенти със злокачествени тумори на глава и шия (както и с други видове тумори). Този хибриден образен метод дава възможност за корегистрация на функционален и анатомичен образ в един (fusion) образ, с възможност за 3D изобразяване, при който ранната промяна в глюкозния метаболизъм в патологичните лезии дава възможност за детекция на патологични промени преди поява на структурни (размерни) промени. Широко използван в цял свят е радиофармацевтикът 18F-FDG, който и ние прилагаме в нашата практика. Този радиофармацевтик представлява глюкоза, маркирана с позитронен 
емитер $18 \mathrm{~F}$, който позволява детекцията на тази субстанция в клетки, натрупващи я интензивно, което ги отграничава от околните, при ПЕТ изследване. В практиката се използва стандартната стойност за полуколичествена оценка на натрупването на радиофармацевтика в туморните клетки (SUVmax). W. Halphpenny et al. посочват, че тя може да бъде изключително полезна за разграничаване на тумори с по-агресивна биологична природа, което е от съществено значение за идентифициране на пациенти, при които се изискват интензивни протоколи за лечение (химиотерапия и лъчелечение). (9) Този екип демонстрира зависимост между стойността на SUVmax над 10 при плоскоклетъчни тумори на глава и шия, независимо от туморния стадий и диаметъра на първичния тумор, като независим прогностичен фактор за лоша прогноза.

При морфологичните образни методи КТ и МРТ малките размери на туморните лезии (под 10 мм) ограничават оценяването им като патологични, което при висока пролиферативна активност и интензивно натрупване на маркираната глюкоза в тях ги прави лесно метаболитно отличими на ПЕТ. 18F-FDG ПЕТ/КТ осигурява функционална оценка от ПЕТ образа, а не само размерната оценка от КТ, което позволява детекция на метастатични лимфни възли, дори те да са клинично негативни. Ограничение съществува както при КТ, така и при МРТ при търсене на рецидиви. Точността им се затруднява след хирургично лечение или третиране на тъканите с лъчелечение, поради промяна в анатомията на структурите. Това затруднява диференциалната диагноза на рецидив с постоперативни, постлъчетерапевтични промени и фиброза. В такива случаи за точна диагноза се прилага целотелесният FDG ПЕT/КТ. При този неинвазивен образен метод чрез оценка на метаболитната активност в подлежащите структури нуклеарният медик има възможност да направи точна диференциална диагноза на рецидив. ПЕТ/КТ позволява целотелесно скениране на пациентите. Това предимство, осигуряващо възможност за ранна детекция на далечни метастази и синхронни тумори, което дава шанс на пациента за своевременно лечение. Въпреки утвърдените преимущества на FDG ПЕТ/КТ при ЗТГШ като основен метод за диагностика, трябва да се има предвид, че при Т-стадиране на първичния тумор КТ и МРТ остават предпочитани образ- ни изследвания поради по-добрата анатомична резолюция и тьканен контраст в сравнение с ПЕТ/КТ без венозен контраст, което не позволява точно делинеиране на локалното разпространение на първичния тумор. Въпреки че FDG ПЕТ/КТ с венозен контраст осигурява детайлен анатомичен и функционален образ, той не се използва рутинно. При метаанализ Rusthoven $\mathrm{KE}$ et al. установяват, че при $25 \%$ от случаите с неясно първично огнище с метастатични шийни лимфни възли ПЕТ/КТ открива първичния тумор със специфичност, чувствителност и точност съответно $88,3 \%, 74,9 \%$ и 78,8\%. (10) B Clinical Oncology (2013), Yoo J et al. препоръчват провеждането на ПЕТ/КТ за детекция на позитивни огнища, суспектни за малигнени и определяне на места за биопсия преди панедоскопия. (11) В проспективно изследване на Jorgen Jahansen et al. ce разглеждат пациенти, при които е била проведена панендоскопия преди ПЕТ/КТ. Екипа установява много фалшиво позитивни резултати при повече от 50\% от пациентите, в следствие на скорошна биопсия или тонзилектомия след панендоскопията. (12) Установена е различна чувствителност на ПЕТ при нодално стадиране 33 - 67\%. (13 - 15) Kovacs AF et al. препоръчват при негативен резултат от ПЕТ пациентьт да проведе синтинелна лимфна биопсия (за детекция на микрометастази, поради ограничение в големината на резолюцията на ПЕТ, 4 мм), същите автори препоръчват при позитивен ПЕТ резултат за хиперметаболитни шийни лимфни възли да се проведе шийна лимфна дисекция, като по този начин се селектират пациентите, при които не е нужно провеждане на хирургична интервенция, и това ще промени терапевтичното поведение. (16)

B проучване S.Y. Kim et al. (17) установяват следните резултати: високи стойности на чувствителност и негативна предсказваща стойност, съответно 97,5\% и 100\% (определящи FDG ПЕT/ КТ като надежден скринингов метод за откриването на синхронни тумори и далечни метастази, при стадиране или при рестадиране след проведено лечение, дори при липса на клинична изява); ниска позитивна предсказваща стойност $60 \%$ (което налага използването на допълнителни образни методи за изключване на фалшиво позитивни резултати); ПЕТ/КТ детектира синхронни тумори и далечни метастази съответно 
4,0\% и 7,4\%, при проследяване на пациентите в двугодишен период. В метаанализ на екипа на Gupta $\mathrm{T}$ et al. стойности за чувствителност, специфичност, позитивна предсказваща стойност и негативна предсказваща стойност, при детекция на резидуален тумор с FDG ПЕТ/КТ са както следва 94\%, 82\%, 75\% и 95\%.(18) Резултатите от този метаанализ утвърждават FDG ПЕТ/КТ като надежден образен метод за изключване на витална туморна тъкан в областта на първичния тумор и региона на шията, поради високата стойност на негативна предсказваща стойност - 95\%. Следователно при негативен ПЕТ/КТ образ и липса на метаболитно активни огнища при пациента може надеждно да се отчете пълен терапевтичен отговор от проведеното лечение и не е необходимо последващо лечение, което утвърждава ролята на метода в посттерапевтичното рестадиране при третирани пациенти.

Много проучвания посочват ПЕТ като метод за детекция на рецидиви с по-висока чувствителност от КТ, МРТ, УЗ и физикалното изследване. (19 - 20) Хибридният ПЕТ/КТ е по-ефективен от ПЕТ, с по-висока точност на метода, редуцира двусмислените резултати, като позволява корелиране на функционалните промени с КТ образ и точно определяне на анатомичната им локализация.

В метаанализ на M.G. Isles et al. за детекция на резидуален тумор след лъчелечение и химиотерапия на пациенти с плоскоклетъчен карцином на глава и шия е установена чувствителност, специфичност, позитивна предсказваща стойност и негативна предсказваща стойност на посттерапевтичния ПЕТ 94\%, 82\%, 75\% и 95\%, като чувствителността е по-висока след 10. седмица от края на лечението. (21) В същия метаанализ от 2008 година, проведен с 1871 пациенти, ПЕТ е посочен като точна образна модалност за надеждна оценка ефекта от лечение, който дава възможност за селекция на пациенти, при които не се налагат допълнителни инвазивни процедури като ендоскопия и шийна лимфна дисекция.

\section{Изводи}

Данните от литературата утвърждават 18F-FDG ПЕТ/КТ като образен метод с важна роля при нодално и далечно стадиране на епителните карциноми на глава и шия, който допълва резул- татите от конвенционалните образни методи (КТ и МРТ остават пьрви избор при Т-стадиране, точно делинеиращи локалното разпространение на първичния тумор). FDG-ПЕT/KT е с водеща роля пред конвенционалните образни методи при нодално стадиране, особено при клинично негативни шийни лимфни възли. При посттерапевтичен FDG-ПЕT/KT методът показва висока негативна предсказваща стойност, осигуряваща изключване на витален тумор. FDG ПЕТ/КТ има високи стойности на чувствителност и негативна предсказваща стойност (определящи метода като надежден скринингов метод за откриването на втори първичен тумор и далечни метастази при стадиране или рестадиране след проведено лечение, дори при липса на клинична изява); с ниска позитивна предсказваща стойност (което налага използването на допълнителни образни методи за изключване на фалшиво позитивни резултати). Установяването на далечни метастази води до промяна в терапевтичния подход от курабилен към палиативен, а откриването на втори първичен тумор води до допълнително включване на лечение и индивидуално планиране на терапевтичния подход. ПЕТ/КТ има висока ефективност при откриване на рецидиви, с основна роля за оценка ефекта от лечение. В литературата се дискутира SUVmax като широко използван предиктивен фактор за отговор от лечение, локорегионален контрол и преживяемост. 18F-FDG ПЕТ/КТ е неинвазивен образен метод, който позволява да се установи първично туморно огнище при пациенти с доказани метастатични шийни лимфни възли от плоскоклетъчен карцином. Хибридният образен метод, проведен след негативни резултати от конвенционални изследвания и клиничен преглед, дава възможност за визуално онагледяване на позитивни огнища, суспектни за малигнени, подходящи за последваща насочена биопсия/ панендоскопия и търсене на вероятен първичен тумор в тази локализация. Все още дискутабилна остава последователността на извършване на FDG-ПЕT/КТ и панендоскопия, ПЕТ/КТ преди или след панендоскопия, като трябва да се отбележи, че извършването на предходни биопсии и тонзилектомия води до повишаване на фалшиво позитивните резултати от ПЕТ/КТ. 


\section{Библиография}

(1). Валерианова 3., Димитрова Н., Вуков М., Атанасов Т. (ред.) Заболеваемост от рак в България, 2013. Български национален раков регистър, София 2015.

(2). Prevalence of human papillomavirus in oropharyngeal and nonoropharyngeal head and neck cancer-systematic review and meta-analysis of trends by time and region.Mehanna H, Beech T, Nicholson T, El-Hariry I, McConkey C, Paleri V, Roberts SHead Neck. 2013 May; $35(5): 747-$ 55.

3. Global cancer statistics, 2002. Parkin DM, Bray F, Ferlay J, Pisani P CA Cancer J Clin. 2005 Mar-Apr; 55(2):74-108. [PubMed] [Ref list]

4. Kim SY, Roh JL, Yeo NK, Kim JS, Lee JH, Choi SH, Nam SY. Combined 18F-fluorodeoxyglucose-positron emission tomography and computed tomography as a primary screening method for detecting second primary cancers and distant metastases in patients with head and neck cancer. Ann Oncol. 2007; 18:1698-1703. [PubMed]

5. Kyzas PA, Evangelou E, Denaxa-Kyza D, Ioannidis JP. 18F-fluorodeoxyglucose positron emission tomography to evaluate cervical node metastases in patients with head and neck squamous cell carcinoma: a meta-analysis. J Natl Cancer Inst. 2008; 100:712-720. [PubMed]

6. Bundhit Tantiwongkosi, Fang Yu, Anand Kanard, and Frank R Miller. Role of 18F-FDG PET/CT in pre and post treatment evaluation in head and neck carcinoma. World J Radiol. 2014 May 28; 6(5): 177-191. Published online 2014 May 28. doi: 10.4329/wjr.v6.i5.177.

7. Ercole Di Martino, MD; Bernd Nowak, MD; Hassan A. Hassan, MD; RalfHausmann; Gerhard Adam, MD; Udalrich Buell, MD;MartinWesthofen, MD. Diagnosis and Staging oh Head and Neck Cancer. A comparison of Modern Imaging Modalities (Positron Emission Tomography, Computer Tomography, Color-Code Duplex Sonography) With Panendoscopic and Histopathlogic Findings. ArhOtotlaryngol Head Neck surg/VOL 126, Dec 2000.

8. Dillon WP. Magnetic resonance imaging of head and neck tumors. CardiovascInterventRadiol. 1986;8 (5-6), 275-82.

9. W. Halfpenny, S F Hain,L Biassoni, M N Maisey, J A Sherman, and M McGurk. FDG-PET. A possible prognostic factor in head and neck cancer. Br J Cancer. 2002 Feb 12; 86(4): 512-516. doi: 10.1038/sj.bjc.6600114

10. Rusthoven KE, Koshy M, Paulino AC. The Role of Fluorodeoxyglucose Positron Emission Tomography in Cervical Lymph Node Metastases from an Unknown Primary Tumor. Cancer. 2004; 101:2641-2649.[PubMed]

11. Yoo J, S. Henderson, C. Walker- Dilks, Evidence-baced guideline recommendation on use of positron emission tomography imaging in the head and neck cancer. Clinical Oncology 2013; 25(4):e33-e66

12. Jorgen Jahansen, Simon Buus,Annika Loft et al.Prospective study of 18F-FDG PET/CT in detection and menagment of patients with lymp node metastases to the neck from an unknown primary tumor. Results from the DAHANCA-13. Nead Neck. Journal of the sciences and specialtiest of the head and neck. 19 November 2017.https://doi.org/10.1002/hed.20734

13. Ng SH, Yen TC, Chang JT, et al, Prospective study of $18 \mathrm{~F}$ fluorodeoxyglucose positron emission tomography and computed tomography and magnetic resonance imaging in oral cavity squamous cell carcinoma with palpable negative neck. J ClinOncol 2006; 24(27):4371-4376.

14. Schoder H, Carlson DL, Kraus DH, et al. 18F-FDG PET/CT for detecting nodal metastases in patient with patients with oral cancer staged N0 by clinical examination and CT/MRI. J Nucl Med 2006; 47(5):755-762.

15. Wensing BM, Vogel WV, Marres HA, et al, FDG-PET in clinically negative neck in oral squamous cell carcinoma. Laryngoscope 2006;116(5):809-813.

16. Kovac AF, Dobert N, Gaa J, et al, Positron emission tomography in combination with sentinel node biopsy reduced the rate of elective neck dissection in the treatment of oral and oropharengeal carcinoma. J ClinOncol 2004; 22(19):3973-3980.

17. S.Y.Kim, J.-L.Roh, N.-K.Yeo, J.S.Kim, J.H.Lee, S,H.Choi\&S.Y.Nam, Combined 18F-fluorodeoxyglucose-positron emission tomography and computed tomography as a primary screening method for detecting second primary cancers and distant metastases in patients with head and neck cancer.

18. Gupta T, Master Z, Kannan S, Agarwal JP, Ghsoh-Laskar S, Rangarajan V, Murthy V, Budrukkar A. Diagnostic performance of post-treatment FDG PET or FDG PET/CT imaging in head and neck cancer: a systematic review and meta-analysis. Eur J Nucl Med Mol Imaging. 2011; 38:2083-2095. [PubMed]

19. Adams S., Baum R.P., Stuckensen T., Bitter K., Hor G. Prospective comparison of 18F-FDG PET with conventional imaging modalities (CT, MRI, US) in lymph node staging of head and neck cancer. Eur J Nucl Med. 1998; 25:1255-1260. [PubMed].

20. Schoder H, Yeung HW. Positron emission imaging of head andneck cancer, including thyroid carcinoma. SeminNucl Med.2004; 34:180197.

21. M.G. Isles, C. McConkey, H.M. Mehanna. A systematic review and meta-analysis of the role of positron emission tomography in the follow up of head and neck squamous cell carcinoma following radiotherapy or chemoradiotherapy. 5 June 2008 DOI: 10.1111/j.17494486.2008.01688. 